\title{
REALTIME MONITORING ANTRIAN PENDAFTARAN PASIEN PUSKESMAS BERBASIS ANDROID DALAM UPAYA PENANGGULANGAN PENYEBARAN COVID-19
}

\author{
Rohmat Gunawan 1,a*, Alam \\ Rahmatulloh ${ }^{2, a}$, Laely Armiyati, ${ }^{3, b}$, \\ Aldy Putra Aldya ${ }^{4, a}$ \\ aprogram Studi Informatika \\ Fakultas Teknik \\ Universitas Siliwangi \\ bProgram Studi Pendidikan Sejarah \\ Fakultas Keguruan dan Ilmu Pendidikan \\ Universitas Siliwangi \\ ${ }^{1}$ rohmatgunawan@unsil.ac.id \\ 2alam@unsil.ac.id \\ 3laely.armiyati@unsil.ac.id \\ 4aldy@unsil.ac.id \\ * Corresponding author
}

\begin{abstract}
ABSTRAK
Antrian konvensional menjadi polemik yang umum di masyarakat. Lamanya proses pelayanan dan waktu tunggu antrian konvensional sangat mengganggu aktivitas sehari-hari. Di instansi kesehatan seperti Pusat Kesehatan Masyarakat (PUSKESMAS), Rumah Sakit dan Poliklinik, bahkan proses antrian harus dilakukan oleh pasien sebagai pendaftar sebelum dapat dilayani. Untuk mengatasi masalah tersebut diusulkan sistem antrian digital berbasis mobile yang dapat diakses secara online. Pendaftar dapat melakukan registrasi melalui aplikasi eAntrian di smartphone yang terkoneksi dengan internet. Informasi nomor antrian akan diperoleh setelah pendaftaran dinyatakan valid. Selain itu, pendaftar juga mendapatkan informasi laju nomor antrian yang sedang dilayani secara realtime. Hasil dari kegiatan pengabdian ini antara lain: sosialisasi diikuti oleh 13 pegawai Puskesmas, demo aplikasi, uji coba aplikasi dan diskusi terkait aplikasi eAntrian. Login sebagai pengguna dan pengelola pada aplikasi berhasil dilakukan. Ketika login sebagai pengelola, jenis layanan yang disediakan berhasil dibuat dan dapat ditambah sesuai kebutuhan. Monitoring proses antrian dibantu dengan tampilan jumlah pedaftar pada setiap layanan dan laju nomor antrian yang sedang dilayani. Sedangkan ketika login sebagai pengguna, informasi nomor antrian berhasil ditampilkan di smartphone pengguna dan sistem berhasil menampilkan laju nomor antrian secara real-time.
\end{abstract}

KATA KUNCI: antrian, monitoring, pendaftaran, real-time

\section{PENDAHULUAN}

Antrian konvensional sudah menjadi polemik yang umum di masyarakat. Lamanya proses dan waktu tunggu antrian konvensional sangat mengganggu aktivitas sehari-hari. Pada instansi kesehatan seperti Pusat Kesehatan Masyarakat (Puskesmas), Rumah Sakit dan Poliklinik, bahkan proses mengantri juga harus dilakukan oleh pasien sebagai pendaftar sebelum dapat dilayani [1]. Apalagi di era pandemi Covid-19 ini yang mengharuskan adanya jaga jarak, berbagai upaya telah dilakukan seperti sistem pemantau sebaran Covid-19 [2].

Beberapa cara untuk menangani masalah antrian telah dikembangkan sebelumnya, diantaranya: analisis sistem antarian [3], [4], sistem pendaftaran antrian berbasis SMS Gateway [5], [6], sistem pendaftaran online [7], [8]. Sistem pedaftaran antrian berbasis SMS Gateway memerlukan pulsa untuk dapat berkomunikasi melalui SMS dan semakin jarang penggunaanya.
Pendaftaran online berbasis web atau berbasis mobile dengan menggunakan internet merupakan salah satu solusi yang dapat dilakukan untuk menyelesaikan masalah ini. Pada sistem pendaftaran online, nomor antrian biasanya diperoleh secara elektronik setelah proses pendaftaran dinyatakan valid. Pendaftaran dapat dilakukan di mana saja yang dapat dilakukan melalui smartphone, tablet PC atau laptop [9]-[11]. Pendaftar akan mendapatkan nomor antrian secara elektronik melalui aplikasi, sehingga tidak diperlukan lagi kertas nomor antrian seperti pada sistem antrian konvensional.

Namun informasi laju nomor antrian yang sedang dilayani di lokasi tidak dapat diketahui. Sehingga ketika pendaftar yang telah mendapatkan nomor antrian elektronik datang ke lokasi pelayanan, nomor antrian yang sedang dilayani jaraknya masih jauh dari nomor antrian yang diperloleh, sehingga masih harus menunggu selama rentang wantu tertentu. Bahkan mungkin nomor antrian yang dimiliki telah melewati pemanggilan, karena datang terlambat. Hal ini terjadi 
karena pendaftar tidak mendapatkan informasi laju nomor antrian yang dilayani di lokasi secara real-time.

Pada kegiatan pengabdian ini akan dilakukan implementasi sistem antrian digital berbasis mobile. Pendaftar dapat melakukan registrasi melalui aplikasi elektronik Antrian (eAntrian) di smartphone yang terhubung ke internet. Informasi nomor antrian akan diperoleh setelah proses pendaftaran dinyatakan valid. Selain dari itu, pendaftar juga mendapatkan informasi laju nomor antrian yang sedang dilayani secara realtime. Kegiatan pengabdian ini juga disertai pelatihan penggunaan aplikasi dan pengelolaan sistem eAntrian serta monitoring proses antrian secara real-time. Selain itu, proses pendampingan juga dilakukan agar sistem dapat berjalan sesuai dengan tujuan di lokasi mitra.

\section{METODE PELAKSANAAN}

Terdapat beberapa aktivitas yang dilakukan pada kegiatan pengabdian ini. Secara umum terdapat tiga tahapan yang dilakukan: persiapan, pelaksanaan, penutup. Berikut aktivitas yang dilakukan dari setiap tahapan kegiatan:

A. Persiapan

1. Pada tahap ini dilakukan kunjungan awal ke lokasi mitra pengabdian.

2. Pengumpulan informasi terkait sistem antrian yang sedang berjalan di lokasi mitra pengabdian.

3. Analisis masalah yang dihadapi dalam ruang lingkup sistem antrian yang berjalan di lokasi mitra pengabdian.

\section{B. Pengembangan Aplikasi eAntrian}

1. Pada tahap ini dilakukan pengembangan aplikasi eAntrian berbasis mobile yang dapat diakses melalui jaringan internet.

2. Uji coba aplikasi eAntrian.

3. Hosting aplikasi eAntrian agar dapat diakses melalui jaringan internet internet.

\section{Pelaksanaan}

1. Sosialisasi aplikasi eAntrian.

2. Demo apliksi eAntrian.

3. Uji coba aplikasi eAntrian oleh pengguna akhir.

4. Diskusi terkait aplikasi eAntrian dengan pengguna di lokasi mitra pengabdian.

\section{HASIL KEGIATAN}

Secara umum terdapat beberapa tahap yang dilakukan pada saat pelaksanaan kegiatan pengabdian, seperti ditampilkan pada gambar 1 .

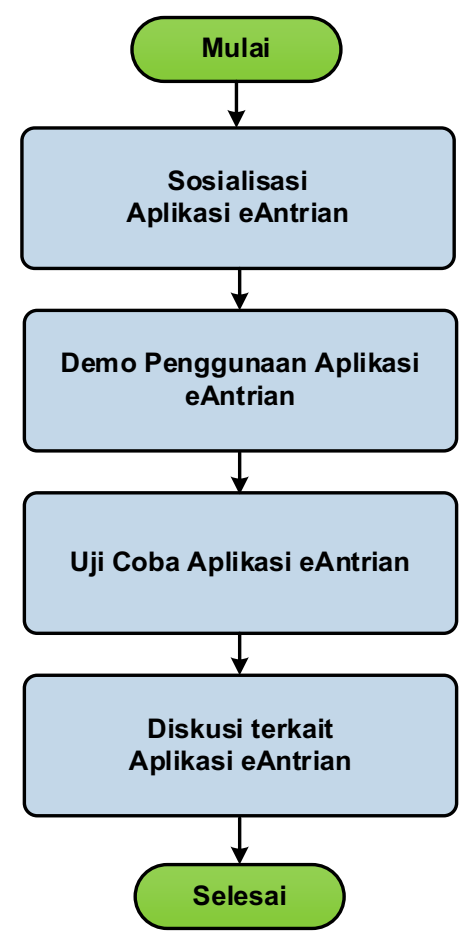

Gambar 1. Tahap Pelaksanaan Kegiatan Pengabdian

Kegiatan Pengabdian Kepada Masyarakat dilaksanakan pada hari Senin 26 Oktober 2020, berlokasi di Unit Pelaksana Teknis Daerah (UPTD) Puskesmas Tinewati Kabupaten Tasikmalaya. Kegiatan pengabdian diawali dengan sosialisasi aplikasi eAntrian kedapa karyawan Puskesmas seperti ditampilkan pada gambar 2.

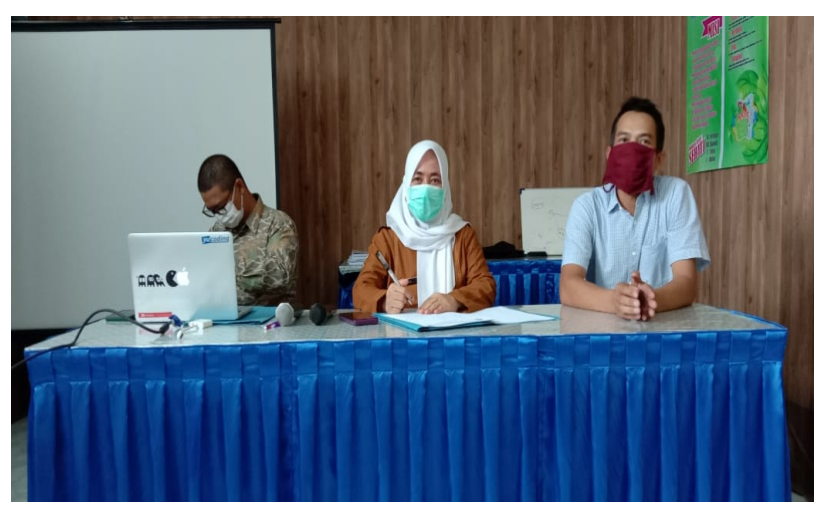

Gambar 2. Sosialisasi Aplikasi eAntrian

Setelah sosialisasi aplikasi eAntrian, tahap berikutnya yaitu demo aplikasi. Aktivitas yang dilakukan yaitu mengakses aplikasi dengan cara login, sampai dapat mengakses menu utama. Demo aplikasi oleh Tim 
pelaksana kegiatan pengabdian ditampilkan pada gambar 3 .

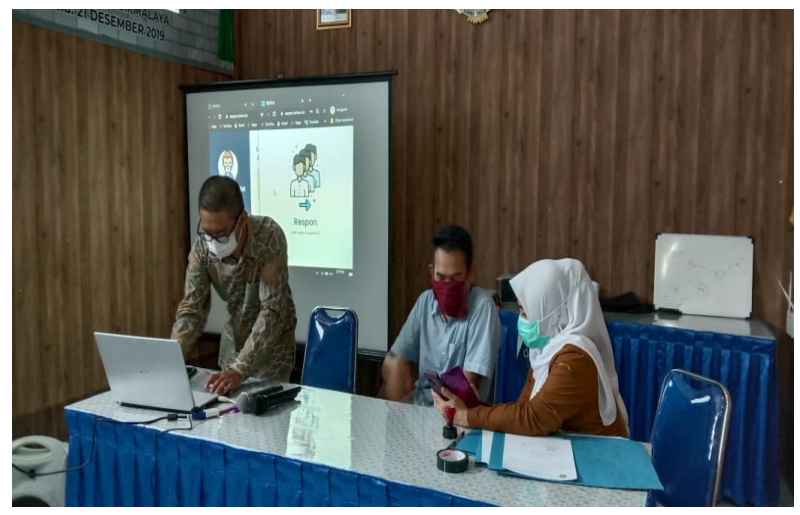

Gambar 3. Demo Aplikasi eAntrian

Aplikasi yang dikembangkan dirancang untuk dapat diakses melalui smartphone. Aplikasi yang dikembangkan dapat diakses melalui internet pada tautan respon.kintun.id. Halaman utama aplikasi ditampilkan pada gambar 4.

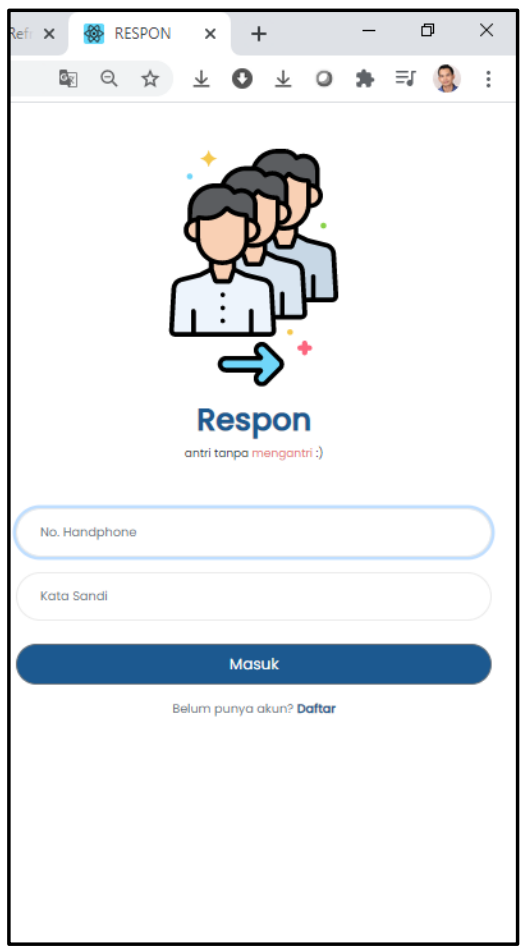

\section{Gambar 4. Halaman Awal Aplikasi eAntrian}

Gambar 4 merupakan halaman utama aplikasi dengan tagline "Respon", yang merupakan singkatan dari Sistem Reservasi Pendaftaran dan Antrian Online.
Aplikasi dapat digunakan dengan melakukan registrasi sebelumnya. Nomor telepon dan kata sandi harus diinput pada saat registrasi. Login dapat dilakukan setelah proses registrasi dinyatakan valid. Ketika Login berhasil dilakukan, maka akan ditampilkan menu utama aplikasi eAntrian seperti ditampilkan pada gambar 5 .

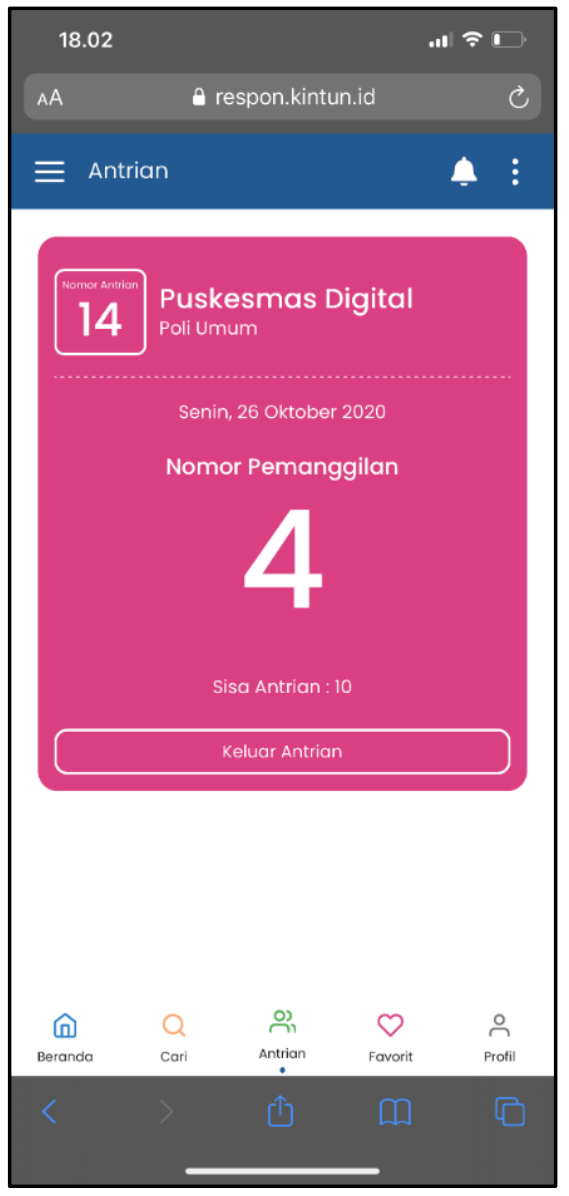

\section{Gambar 5. Menu Utama Aplikasi eAntrian Login sebagai pengguna}

Terdapat beberapa informasi yang ditampilkan oleh aplikasi. Pertama, naama institusi yang ditampilkan paling atas. Pada gambar 4, "Puskesmas Digital" merupakan nama institusi penyedia layanan. Angka "14" merupakan nomor antrian yang diperoleh setelah pengguna berhasil melakukan pendaftaran. Sedangkan angka " 4 " merupakan nomor antrian terakhir yang sedang dilayani, dan akan berubah sesuai laju nomor antrian. Informasi perubahan laju nomor antrian ini ditampilkan secara real-time kepada pengguna sesuai dengan yang terjadi di lokasi layanan. Laju perubahan nomor antrian yang ditampilkan secara real-time pada smartphone pengguna, bermanfaat untuk memberikan 
informasi estimasi waktu layanan sesuai dengan nomor urut antrian yang didapatkan.

Aplikasi juga dirancang untuk dapat membantu mengelola dan memantau proses antrian yang sedang berjalan. Ini hanya dapat dilakukan oleh pihak penyedia layanan. Secara umum tampilan halaman bagi pihak pengelola ditampilkan pada gambar 6 .

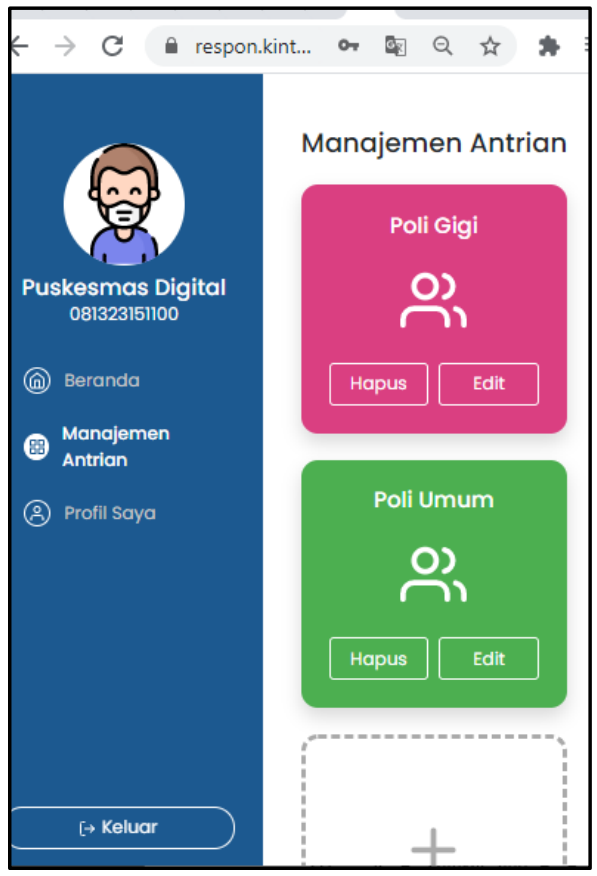

\section{Gambar 6. Menu Utama Aplikasi eAntrian Login sebagai pengelola}

Pada gambar 6 ditampilan beberapa contoh layanan yang dibuat oleh institusi penyedia layanan pada saat konfigurasi awal. Jumlah layanan dapat ditambah sesuai dengan kebutuhan. "Poli Gigi" dan "Poli Umum" merupakan contoh layanan yang tersedia pada sistem, yang siap menerima antrian pasien.

Aplikasi yang dikembangkan dicoba langsung oleh setiap karyawan Puskesmas yang mengikuti acara sosialisasi pada waktu itu. Pendampingan saat uji coba aplikasi dilakukan untuk memastikan aplikasi dapat berfungsi sesuai tujuan yang diharapkan, seperti ditampilkan pada gambar 7 .

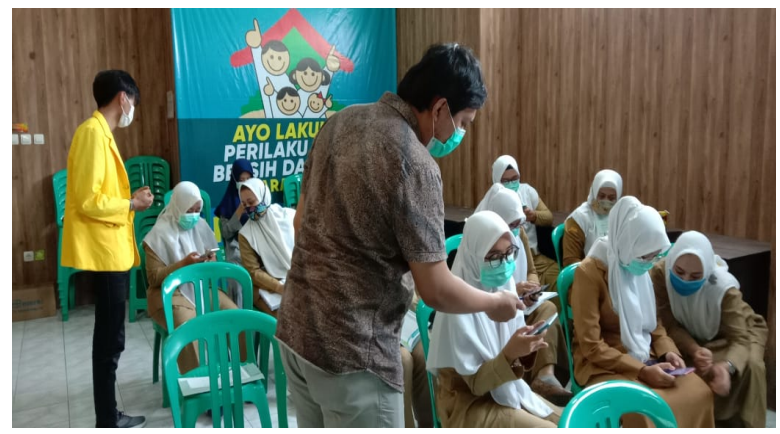

\section{Gambar 7. Pendampingan pada saat uji coba Aplikasi eAntrian}

Setelah dilakukan uji coba, tahap berikutnya diselenggarakan tanya jawab seputar aplikasi eAntrian. Setelah selesai kemudian acara ditutup oleh Kepala Puskesmas di lokasi mitra pengabdian.

\section{PENUTUP}

Sosialisasi dan uji coba aplikasi eAntrian berbasis mobile telah dilakukan di lokasi mitra pengabdian. Agar proses implementasi dapat berjalan dengan baik, penyedia layanan dalam hal ini Puskesmas perlu melakukan input data jenis layanan (misal: Poli Umum, Poli Gigi, Poli Telinga Hidung Tenggorokan/THT), yang akan digunakan oleh masyarakat agar sistem dapat berjalan sesuai tujuan.

\section{UCAPAN TERIMA KASIH}

Syukur kami panjatkan kepada Allah SWT karena atas ridha-Nya kegiatan pengabdian ini dapat terlaksana. Tidak lupa kami sampaikan ucapan terima kasih yang sebesar-besarnya kepada:

1. LP2M-PMP Universitas Siliwangi yang telah mendukung dan memberikan dana kegiatan.

2. UPTD Puskesmas Tinewati Kabupaten Tasikmalaya Jawa Barat yang telah menjadi mitra kegiatan ini.

3. Rekan-rekan Dosen Universitas Siliwangi.

\section{DAFTAR PUSTAKA}

[1] R. A. Zulfikar and A. A. Supianto, "Rancang Bangun Aplikasi Antrian Poliklinik Berbasis Mobile," Jurnal Teknologi Informasi dan IImu Komputer, vol. 5, no. 3, p. 361, 2018.

[2] F. Al Isfahani, F. Nugraha, R. Mubarok, and A. Rahmatulloh, "Implementasi Web Service untuk Aplikasi Pemantau Coronavirus Disease 2019 
(COVID-19)," Innovation in Research of Informatics (INNOVATICS), 2019.

[3] P. Wigati, A. Suparwati, and A. Fuanasari, "Analisis Alur Pelayanan Dan Antrian Di Loket Pendaftaran Pasien Rawat Jalan," Jurnal Kesehatan Masyarakat (e-Journal), vol. 2, no. 1, pp. 15-21, 2014.

[4] S. Wihdaniah, M. Pono, and M. Munizu, "Queue System Performance Analysis in Optimizing," Bisnis, Manajemen dan Informatika, pp. 228238, 2018.

[5] W. Musu, "Perancangan Sistem Informasi Antrian Berbasis SMS Getway Pada Klinik Herona Medical Pare Pare," in Seminar Nasional Informatika 2015, 2015, pp. 68-72.

[6] H. Lubis, I. D. Nirmala, and S. E. Nugroho, "Perancangan Sistem Informasi Antrian Online Pasien RS. Seto Hasbadi menggunakan SMS Gateway Berbasis Android," Jurnal Algoritma, vol. 16, no. 2, pp. 79-91, 2020.

[7] A. Hidayati, "Perancangan Dan Pembuatan Aplikasi Pendaftaran Mahasiswa Baru," ELTEK, vol. 11, no. 2, pp. 67-78, 2013.

[8] C. Pusparani, B. Priyambadha, and A. Arwan, "Pembangunan Sistem Aplikasi Rekam Medis Elektronik Dan Pendaftaran Pasien Online Berbasis Web Studi Kasus Klinik Medis Elisa Malang," Pengembangan Teknologi Informasi dan Ilmu Komputer, vol. 3, no. 2, pp. 1458-1463, 2019.

[9] H. O. L. Wijaya, "Penerapan Metode Waterfall Pada Sistem Informasi Pendaftaran Pasien Rawat Jalan Berbasis Web Mobile," Jurnal Sisfokom (Sistem Informasi dan Komputer), vol. 6, no. 2, p. 80, 2017.

[10] F. N. Adnan, "Aplikasi mobile berbasis android untuk Administrasi Pemeriksaan Poliklinik Rawat Jalan di RSUD Kota Salatiga," 2009.

[11] W. Agung and B. Mobile, "Aplikasi antrian dan pelayanan pada klinik wijaya agung berbasis mobile," in Seminar Nasional Sistem Informasi dan Teknik Informatika, 2019, pp. 1147-1155. 